\title{
Prediction of Depression in Schizophrenia: Can serum Levels of BDNF or EGF Help us?
}

Ebru Oztepe Yavasci ${ }^{1}$, Salih Saygin Eker ${ }^{2}$, Sengul Cangur ${ }^{3}$, Selcuk Kirli $^{4}$ and Emre Sarandol ${ }^{5}$

${ }^{1} M D$, Uludag University Medical Faculty Department of Psychiatry, Bursa, Turkey,

2Associate Professor, Uludag University Medical Faculty Department of Psychiatry, Bursa, Turkey

${ }^{3}$ Assistant Professor, PhD, Duzce University Medical Faculty, Department of Biostatistics, Duzce, Turkey

${ }^{4}$ Professor, MD, Psychiatrist, Uludag University Medical Faculty Department of Psychiatry, Bursa, Turkey

${ }^{5} \mathrm{MD}$, Professor, Uludag University Medical Faculty Department of Biochemistry, Bursa, Turkey

*Correspondent author: Salih Saygin Eker, Associate Professor, M.D, Uludag University Medical Faculty, Department of Psychiatry, Bursa, Turkey; Tel: 902242951840; E-mail: saygineker@yahoo.com

Received Date: June 9, 2014, Accepted Date: September 23, 2014, Published Date: September 30, 2014

Copyright: ( 2014 , Ebru Oztepe Yavasci et al., This is an open-access article distributed under the terms of the Creative Commons Attribution License, which permits unrestricted use, distribution, and reproduction in any medium, provided the original author and source are credited.

\begin{abstract}
Today, it is known that the levels of neurotrophic factors alter in neuropsychiatric disorders such as major depressive disorder (MDD), schizophrenia, Alzheimer's disease or Parkinson's disease. In recent years, some studies demonstrated that MDD may occur as a result of the changes in neuronal plasticity at structural and molecular levels.
\end{abstract}

Keywords: Schizophrenia; Depression; BDNF; Serum levels

\section{Introduction}

Neurotrophic factors play an important role in both neurogenesis and neuronal plasticity [1]. Today, it is known that the levels of neurotrophic factors alter in neuropsychiatric disorders such as major depressive disorder (MDD), schizophrenia, Alzheimer's disease or Parkinson's disease [2-4]. In recent years, some studies demonstrated that MDD may occur as a result of the changes in neuronal plasticity at structural and molecular levels $[5,6]$. Many studies demonstrated reduced levels of brain-derived neurotrophic factor (BDNF) in patients with MDD $[7,8]$ and increased levels of serum BDNF following an adequate antidepressant treatment or ECT $[9,10]$. Many studies involving patients with schizophrenia found alterations in serum levels of BDNF. Some of the studies reported no significant differences in serum levels of BDNF between patients and normal controls [11,12] some reported decreased serum levels of BDNF in treated or first-episode schizophrenic patients [13,14]. Epidermal growth factor (EGF) is a well-known neurotrophic factor that involve in neuronal growth and synaptic plasticity [15]. Several studies reported the relationship between EGF levels and neuropsychiatric disorders such as schizophrenia, autism and Parkinson's disease $[3,16]$. Although, the EGF association has been reported in aforementioned neuropsychiatric disorders, it has not been well documented with MDD. Tian et al. [17] are the first to demonstrate that the plasma EGF levels in patients with MDD were significantly lower than those in the control participants. They also concluded that the EGF levels may be used as biomarkers for the early diagnosis and prognosis of psychiatric disorders. The BDNF association has been well documented with MDD or schizophrenia. However, to the best of our knowledge, the EGF association with psychiatric disorders particularly with schizophrenia has not been studied extensively. In this study, we aim to investigate the serum levels of BDNF and EGF in patients with schizophrenia with or without depression.

\section{Materials and Method}

\section{Subjects}

Study population comprised of patients diagnosed with schizophrenia (SZ), major depressive disorder (MDD) and schizophrenia with depression (SZD) and a healthy control group between 18-65 years of age. A total of 47 subjects (11 SZ patients, 20 MDD patients, and 16 SZD patients) were enrolled in the study in this cross-sectional study. The control group comprised 20 healthy subjects. Sociodemographic information was taken for all the participants. The patients were interviewed and diagnosed on the basis of the Diagnostic and Statistical Manual of Mental Disorders, Fourth Edition (DSM-IV, American Psychiatric Association, 1994). SZD group of patients were comprised of patients with schizophrenia meeting the DSM- IV diagnostic criteria for depression. Patients who have an alcohol or drug addiction, patients diagnosed with depression or a psychotic disorder based on a general medical condition or substance use, and patients diagnosed with Axis-1 or Axis-2 disorders other than SZ or MDD were excluded from the study.

The Positive and Negative Symptoms Scale (PANSS), the Calgary Depression Scale for Schizophrenia (CDSS), and the Hamilton Depression Rating Scale (HDRS) were used for assessment. In this study cutoff scores for HDRS and CDSS were set at 8 and 12 respectively $[18,19]$.

The study protocols were approved by the relevant ethics committee. All the procedures that contributed to this work comply with the ethical standards of the relevant national and institutional committees on human experimentation and with the Helsinki Declaration of 1975, as revised in 2008. All the subjects gave their written informed consent to participate. 
Page 2 of 5

\section{BDNF and EGF ELISA}

Blood samples were taken from the patient and control groups from the antecubital vein after 12 hours of fasting between 08:00 and 10:00 am at the biochemistry laboratory of the institution. The samples were studied at the same laboratory. The serums obtained from blood samples taken for the BDNF and IL-2 parameters were preserved in $-80^{\circ} \mathrm{C}$ until they were studied. The blood samples were stored as long as 18 months. The BDNF and EGF were studied by using EnzymeLinked Immuno Sorbent Assay (ELISA) kits (Boster Biological Technologies, China). The BDNF and EGF values were defined as $\mathrm{ng} / \mathrm{ml}$ and $\mathrm{pg} / \mathrm{ml}$, respectively.

\section{Statistical analysis}

The descriptive statistics of the data in the study have been calculated. Whether the data are normally distributed is examined by a Kolmogorov-Smirnov test. The comparisons of the groups are conducted with a Kruskal-Wallis test and/or a Mann-Whitney U test. A Dunn-Bonferroni test is used for multiple comparisons. A Spearman Correlation test has been used to determine the relationship between the continuous variables. To compare the categorical variables, Pearson's Chi-square, Fisher' Exact and Fisher-Freeman Halton tests have been used. The level of significance is set at $\mathrm{p}=0.05$. healthy subjects. There were no significant differences between the three patient groups and the control group in terms of sex $(\mathrm{p}=0.096)$ or age $(p=0.188)$. There were no significant differences between the patient groups in terms of the age of onset of the disorders $(p=0.061)$. However, the duration of the disorders were longer and the relapses were more frequent in the SZ and SZD groups compared to the MDD group $(\mathrm{p}<0.001)$. There were no significant differences between the patient groups in terms of family history $(\mathrm{p}=0.583)$ or suicide attempts $(p=0.065)$. Socio-demographic information of the participants is shown in Table 1. The SZ and MDD groups were drug-free, but 10 of the $16 \mathrm{SZD}$ patients were under treatment ( 7 of the patients were undergoing atypical antipsychotic treatment, and 3 were undergoing atypical antipsychotic and antidepressant combination treatment). The patients were free of extrapyramidal side effects of the antipsychotics. Compared to the control group serum BDNF levels were found significantly lower in the SZ, MDD and SZD groups ( $p=0.049, p=0.001, p=0.01$, respectively). There were no significant differences between the patient groups in terms of serum levels of BDNF ( $\mathrm{p}=0.236)$. Serum levels of EGF did not differ in the MDD $(p=1.00), S Z(p=1.00)$ or SZD $(p=0.218)$ groups compared to the healthy controls.

\section{Results}

A total of 47 subjects (11 SZ patients, 20 MDD patients, and 16 SZD patients) were enrolled in the study. The control group comprised 20

\begin{tabular}{|c|c|c|c|c|c|}
\hline & & Schizophrenic patients & Depressive patients & $\begin{array}{l}\text { Depressed schizophrenic } \\
\text { patients }\end{array}$ & Healthy control \\
\hline Sex & Male & 7 & 6 & 11 & 11 \\
\hline & female & 4 & 14 & 5 & 9 \\
\hline Age & & $39.9 \pm 11.4$ & $39.9 \pm 9.78$ & $34.6 \pm 9.14$ & $35.2 \pm 6.19$ \\
\hline Age & & $26.8 \pm 9.4$ & $31.1 \pm 9.5$ & $23.3 \pm 9.3$ & NA \\
\hline Dura & ness (months) & $144 \pm 114.3$ & $10 \pm 9.1$ & $127.5 \pm 87.1$ & NA \\
\hline BMI & & $25.2 \pm 2.6$ & $28 \pm 5.6$ & $25.1 \pm 4.7$ & $26.3 \pm 4.4$ \\
\hline $\begin{array}{l}\text { Total } \\
\text { Scor }\end{array}$ & & $\begin{array}{l}93 \pm 15.2 \\
93(70-117)\end{array}$ & NA & $\begin{array}{l}90 \pm 13.7 \\
94.5(55-111)\end{array}$ & NA \\
\hline HAM & & NA & $\begin{array}{l}25.2 \pm 4.6 \\
25.5(17-33)\end{array}$ & NA & NA \\
\hline CDS & & $\begin{array}{l}0.8 \pm 1.8 \\
0(0-5)\end{array}$ & NA & $\begin{array}{l}15.5 \pm 2.7 \\
14.5(13-21)\end{array}$ & NA \\
\hline
\end{tabular}

Table 1: Clinical and demographic features of study subjects, Mean \pm Standard Deviation; Median (Min-Max)

There were not any significant correlations between serum levels of BDNF and sex or BMI values for both the patient group $(p=0.246$, $\mathrm{r}=0.076 \mathrm{p}=0.613)$ and the healthy controls $(\mathrm{p}=0.295, \mathrm{r}=0.337 \mathrm{p}=0.146)$. Sex or BMI values also did not seem to affect serum levels of EGF in both the patient group $(\mathrm{p}=0.238, \mathrm{r}=-0.102 \mathrm{p}=0.516)$ and the healthy controls $(\mathrm{p}=0.131, \mathrm{r}=-0.151 \mathrm{p}=0.525)$. Numbers of relapses or suicide attempts were not related to serum levels of BDNF ( $r=0.173 \mathrm{p}=0.246$, $\mathrm{p}=0.144$ respectively $)$ and $\mathrm{EGF} \quad(\mathrm{r}=0.059 \quad \mathrm{p}=0.709, \quad \mathrm{p}=0.338$ respectively). However, duration of the disorders were related to serum levels of BDNF $(\mathrm{r}=0.389 \mathrm{p}=0.007)$ while it was not related to serum levels of EGF $(r=0.216 \mathrm{p}=0.164)$. There were not any significant correlations between age and serum levels of BDNF in the patient groups $(\mathrm{r}=0.239, \mathrm{p}=0.106)$ and the healthy control group $(\mathrm{r}=0.128$, $\mathrm{p}=0.590)$. There was a negative correlation between age and serum levels of EGF in the patient group $(r=-0.392, p=0.009)$, whereas there was no significant correlation between age and serum levels of EGF in 
Page 3 of 5

the healthy control group $(\mathrm{r}=-0.313, \mathrm{p}=0.178)$. There were not any significant correlations between serum levels of BDNF and PANSS $(\mathrm{r}=0.401, \mathrm{p}=0.222)$ or CDDS $(\mathrm{r}=-0.310, \mathrm{p}=0.353)$ scores in the SZ group. There were not any significant correlations between serum levels of EGF and PANSS $(\mathrm{r}=0.176, \mathrm{p}=0.651)$ or CDDS $(\mathrm{r}=-0.639, \mathrm{p}=0$. 064) scores in the SZ group. There were not any significant correlations between serum levels of BDNF and HDRS ( $\mathrm{r}=-0.253$, $\mathrm{p}=0.282$ ) scores in the MDD group. There were not any significant correlations between serum levels of EGF and HDRS ( $r=-0.455$, $\mathrm{p}=0.050)$ scores in the MDD group. There were significant correlations between serum levels of EGF and CDSS $(r=0.154$, $\mathrm{p}=0.584)$ or PANSS $(\mathrm{r}=0.342, \mathrm{p}=0.213)$ scores in the SZD group. There were significant correlations between serum levels of BDNF and CDSS $(\mathrm{r}=0.135, \mathrm{p}=0.617)$, PANSS $(\mathrm{r}=0.183, \mathrm{p}=0.498)$ scores in the SZD group. Tables 1 and 2, demonstrate clinical and demographic features of study subjects and mean serum levels of EGF and BDNF in study subjects, respectively.

\section{Discussion}

The following are the major findings of the present study: i) the serum BDNF levels are lower in all three patient groups than in the control group; ii) the serum levels of EGF were not different from the control group; iii) there were no significant differences between the patient groups in terms of the serum BDNF and EGF levels. In the medical literature, there are some studies that demonstrate that the serum BDNF levels in schizophrenic patients are lower than those in healthy controls $[3,20,21]$ but some studies demonstrate higher serum BDNF levels in schizophrenic patients than in healthy controls [12,22]. There are many studies that demonstrate that patients with MDD have lower levels of serum BDNF than do control patients $[4,7,23]$.

\begin{tabular}{|l|l|l|}
\hline & EGF $(\mathbf{p g} / \mathbf{m l})$ & BDNF(ng/ml) \\
\hline Schizophrenic patients & $157.9 \pm 81.9$ & $15.4 \pm 3.2$ \\
& $148.1(29.2-274.5)$ & $14.8(11-22.4)$ \\
\hline Depressed schizophrenic patients & $205.5 \pm 87.2$ & $14.0 \pm 4.3$ \\
\hline Depressive patients & $201.1(73.8-348.5)$ & $14.6(0.4-19.7)$ \\
\hline Healthy controls & $131.5 \pm 112.0$ & $12.5 \pm 4.5$ \\
& $100.3(36.5-541.5)$ & $12.8(2.4-18.9)$ \\
\hline
\end{tabular}

Table 2: The descriptive statistics of serum levels of EGF and BDNF in study subjects, Mean \pm Standard Deviation; Median (Min-Max)

In line with the aforementioned studies, the present study demonstrates decreased levels of serum BDNF in depressed patients. The accumulated data to date have raised the question of whether the alterations in serum BDNF levels are a part of the pathophysiology of both schizophrenia and MDD. The study by Esen-Danaci et al. has a very limited sample size of SZD patients, but this study reported decreased levels of serum BDNF in MDD patients compared to healthy controls and SZD patients [24]. However, the levels of serum BDNF in SZD patients were similar to those in healthy controls. Noto et al. [25] reported increased levels of serum BDNF in SZD patients whose CSDD scores were above 7 compared to those whose scores were below 7. Present study demonstrates decreased levels of serum BDNF in the SZD patients compared to the healthy controls.

Buckely et al. reported significant correlation between serum levels of BDNF and positive symptoms. Zhang et al. reported a significant correlation between serum levels of BDNF and negative symptoms. Chen et al. reported a positive correlation between serum levels of BDNF and PANSS scores. Noto et al. reported a positive correlation between serum levels of BDNF and CDSS scores. In the present study, we did not find any significant correlations between the serum levels of BDNF and the PANSS or CDSS scores in the SZ group [21,25-27].

Some of the previous studies reported that clinical determinants such as sex, smoking status, drinking behaviour and age can affect serum BDNF levels [28,29], however some did not report such association $[7,21,23]$. In the present study, we did not find any significant correlation between the serum BDNF levels and sex, age, age of onset, or body mass index, number of relapses in the patient groups.

It is argued that, alterations in EGF may involve in the pathogenesis of schizophrenia by disrupting dopaminergic or glutamatergic functions [30]. Furthermore, Tian et al. [17] speculated that decreased levels of EGF are a common phenotype in severe forms of psychiatric disorders, not the mild ones. Therefore, it is suggested that, EGF levels may be biomarkers for the early diagnosis and prognosis of severe psychiatric disorders [17]. Futamura et al. [16] and Ikeda et al. [3] reported decreased levels of serum EGF in schizophrenic patients compared to healthy controls. However, Hashimoto et al. [31] reported no significant difference between schizophrenic patients and healthy controls in terms of levels of serum EGF. Futamura et al. [16] did not demonstrate any association between levels of serum EGF and duration of the disorder or antipsychotic treatment. Likewise, Ikeda et al. [3] did not demonstrate any association between levels of serum EGF and age, sex, onset age of the disorder, smoking status or BMI. However, unlike Futamura et al. [16], they reported a positive correlation between levels of serum EGF and duration of the disorder. The findings of the present study do not suggest any correlations between serum levels of EGF and sex, BMI, numbers of relapses or the duration of the disorders. However, age negatively correlated with serum levels of EGF.

The accumulated data regarding the EGF association with MDD is very scarce. To the best of our knowledge, the most extensive study on this particular subject was carried out by Tian et al. [17] They 
demonstrated that the plasma levels of EGF in patients with MDD were significantly lower than those in the control participants. In the present study serum levels of EGF were not different from the control group in MDD or SZ groups. However, serum levels of EGF were higher in SZD group compared to SZ, MDD and control groups. This study has several limitations. The small sample size is the major limitation of the present study. Some patients in the schizophrenia group were on antipsychotic medications, which can be interpreted as another limitation because it is known that antipsychotics might have an effect on levels of BDNF and EGF. However, it is noteworthy that, Futamura et al. [16] reported no alterations in serum BDNF or EGF levels with psychotropic agents. In the present study, no serum BDNF or EGF level differences were detected between the patients who were undergoing treatment and those who were drug naïve. However, serum levels of BDNF and EGF can be affected by hormonal changes [32], the female patients' menstrual cycles were neglected in the present study. Because the storage time of the samples was no longer than 5 years and the subjects were fasting before the samples were taken, we did not expect any influence of these determinants on the BDNF levels in the present study. Diurnal variation has been reported for plasma BDNF levels, but not for serum BDNF levels [33], we also did not expect any influence of diurnal variation on the outcomes of the present study. Despite its limitations, as far as we know, this is the first study that evaluates serum BDNF and EGF levels in patients with schizophrenia with depression compared to not only a healthy control group but a schizophrenia and major depression group.

The findings of the present study suggest that plasticity and immune system changes are involved in the pathogenesis of schizophrenic patients with or without depressive symptomatology. However, the data do not clarify whether the depressive symptoms in schizophrenia occur as a dimension of schizophrenia or as symptoms of major depression that is comorbid to schizophrenia. Further studies with larger samples are needed to determine whether BDNF and EGF might be useful pathophysiological biological indicators of schizophrenia and depression. Such studies may reveal accurate biological indicators, which may help us understand the pathophysiology of psychiatric disorders.

\section{References}

1. Lledo PM, Alonso M, Grubb MS (2006) Adult neurogenesis and functional plasticity in neuronal circuits. Nat Rev Neurosci 7: 179-193.

2. Howells DW, Porritt MJ, Wong JY, Batchelor PE, Kalnins R, et al. (2000) Reduced BDNF mRNA expression in the Parkinson's disease substantia nigra. Exp Neurol 166: 127-135.

3. Ikeda Y, Yahata N, Ito I, Nagano M, Toyota T, et al. (2008) Low serum levels of brain-derived neurotrophic factor and epidermal growth factor in patients with chronic schizophrenia. Schizophr Res 101: 58-66.

4. Sen S, Duman R, Sanacora G (2008) Serum brain-derived neurotrophic factor, depression, and antidepressant medications: meta-analyses and implications. Biol Psychiatry 64: 527-532.

5. Nibuya M, Nestler EJ, Duman RS (1996) chronic antidepressant administration increases the expression of cAMP response element binding protein (CREB) in rat hippocampus. J Neurosci 16: 2365-2372.

6. Sheline YI, Wang PW, Gado MH, Csernansky JG, Vannier MW (1996) Hippocampal atrophy in recurrent major depression. Proc Natl Acad Sci U S A 93: 3908-3913.

7. Karege F, Perret G, Bandolfi G, Schwald M, Bertschy G, et 1. (2002) Decreased serum brain-derived neurotrophic factor levels in major depressive patients. Psychiatry Res 109: 143-8.

8. Lee BH, Kim H, Park SH, Kim YK (2007) Decreased plasma BDNF level in depressive patients. J Affect Disord 101: 239-244.
9. Aydemir O, Deveci A, Taneli F (2005) the effect of chronic antidepressant treatment on serum brain-derived neurotrophic factor levels in depressed patients: a preliminary study. Prog Neuropsychopharmacol Biol Psychiatry 29: 261-265.

10. Piccinni A, Debbio AD, Medda P, Bianchi C, Roncaglia I (2009) Plasma Brain-Derived neurotrophic factor in treatment-resistant depressed patients receiving electroconvulsive therapy. Eur Neuropsychopharmacol 19: 349-55.

11. Huang TL, Lee CT (2006) Associations between serum brain-derived neurotrophic factor levels and clinical phenotypes in schizophrenia patients. J Psychiatr Res 40: 664-668.

12. Reis H, Nicolato R, Barbosa IG, Teixeira do Prado PH, Romano-Silva $\mathrm{MA}$, et al. (2008) Increased serum levels of brain-derived neurotrophic factor in chronic institutionalized patients with schizophrenia. Neurosci Lett 439: 157-159.

13. Pirildar S, Gönül AS, Taneli F, Akdeniz F (2004) Low serum levels of brain-derived neurotrophic factor in patients with schizophrenia do not elevate after antipsychotic treatment. Prog Neuropsychopharmacol Biol Psychiatry 28: 709-713.

14. Rizos EN, Michalopoulou PG, Siafakas N, Stefanis N, Douzenis A, et al. (2004) Association of Serum Brain-Derived Neurotrophic Factor and Duration of Untreated Psychosis in First-Episode Patients with Schizophrenia. Neuropsychobiology 62: 87-90.

15. Wong RW, Guillaud L (2004) the role of epidermal growth factor and its receptors in mammalian CNS. Cytokine Growth Factor Rev 15: 147-156.

16. Futamura T, Toyooka K, Iritani S, Niizato K, Nakamura R, et al. (2002) Abnormal expression of epidermal growth factor and its receptor in the forebrain and serum of schizophrenic patients. Mol Psychiatry 7: 673-682.

17. Tian W, Zhang J, Zhang K, Yang H, Sun Y, et al. (2012) A study of the functional significance of epidermal growth factor in major depressive disorder. Psychiatr Genet 22: 161-167.

18. Williams JB (1988) a structured interview guide for the Hamilton Depression Rating Scale. Arch Gen Psychiatry 45: 742-747.

19. Oksay S, Aksaray G, Kaptanoglu C, Bal C (2000) Validity and Reliability of the Turkish Version of Calgary Depression Scale in Schizophrenic Patients. Turk Psikiyatri Derg 11: 278-284.

20. Rizos EN, Papadopoulou A, Laskos E, Michalopoulou PG, Kastania A, et al. (2010) Reduced serum BDNF levels in patients with chronic schizophrenic disorder in relapse, who were treated with typical or atypical antipsychotics. World J Biol Psychiatry 11: 251-255.

21. Chen da C, Wang J, Wang B, Yang SC, Zhang CX, et al. (2009) Decreased levels of serum brain-derived neurotrophic factor in drug-naïve firstepisode schizophrenia: relationship to clinical phenotypes. Psychopharmacology (Berl) 207: 375-380.

22. Gama CS, Andreazza AC, Kunz M, Berk M, Belmonte-de-Abreu PS, et al. (2007) Serum levels of brain-derived neurotrophic factor in patients with schizophrenia and bipolar disorder. Neurosci Lett 420: 45-48.

23. Lee AH, Lange C, Ricken R, Hellweg R, Lang UE (2011) Reduced brainderived neurotrophic factor serum concentrations in acute schizophrenic patients increase during antipsychotic treatment. J Clin Psychopharmacol 31: 334-336.

24. Esen-Danaci A, Aydemir O, Deveci A, Taneli F, Taskin O (2009) Serum Brain-Derived Neutotrophic Factor (BDNF) Levels in Schizophrenic Patients with Depressive Symptoms: A Preliminary Study. Bulletin of Clinical Psychopharmacology 19: 236-240.

25. Noto CS, Gadelha A, Belangero SI, Smith MA, de Aguiar BW, et al. (2011) Association of biomarkers and depressive symptoms in schizophrenia. Neurosci Lett 505: 282-285.

26. Buckley PF, Pillai A, Evans D, Stirewalt E, Mahadik S (2007) Brain derived neurotropic factor in first-episode psychosis. Schizophr Res 91: $1-5$.

27. Zhang XY, Tan YL, Zhou DF, Cao LY, Wu GY, et al. (2007) Serum BDNF levels and weight gain in schizophrenic patients on long-term treatment with antipsychotics. J Psychiatr Res 41: 997-1004. 
Citation: Yavasci EO, Eker SS, Cangur S, Kirli S, Sarandol E (2014) Prediction of Depression in Schizophrenia: Can serum Levels of BDNF or EGF Help us?. J Psychiatry 17: 1000156. doi:10.4172/1994-8220.1000156

Page 5 of 5

28. Bus BA, Tendolkar I, Franke B, de Graaf J, den Heijer M, et.al. (2012) Serum brain-derived neurotrophic factor: determinants and relationship with depressive symptoms in a community population of middle-aged and elderly people. World J Biol Psychiatry 13: 39-47.

29. Xiu MH, Hui L, Dang YF, Hou TD, Zhang CX, et al. (2009) Decreased serum BDNF levels in chronic institutionalized schizophrenia on longterm treatment with typical and atypical antipsychotics. Prog Neuropsychopharmacol Biol Psychiatry 33: 1508-1512.

30. Hänninen K, Katila H, Anttila S, Rontu R, Maaskola J, et al. (2007) Epidermal growth factor a61g polymorphism is associated with the age of onset of schizophrenia in male patients. J Psychiatr Res 41: 8-14.
31. Hashimoto K, Shimizu E, Komatsu N, Watanabe H, Shinoda N, et al. (2005) No changes in serum epidermal growth factor levels in patients with schizophrenia. Psychiatry Res 135: 257-260.

32. Sohrabji F, Lewis DK (2006) Estrogen-BDNF interactions: implications for neurodegenerative diseases. Front Neuroendocrinol 27: 404-414.

33. Piccinni A, Marazziti D, Del Debbio A, Bianchi C, Roncaglia I, et al. (2008) Diurnal variation of plasma brain-derived neurotrophic factor (BDNF) in humans: an analysis of sex differences. Chronobiol Int 25: 819-826. 